\title{
Eventos tonais pré-nucleares de declarativas e interrogativas neutras do português do Libolo em fala semiespontânea
}

DOI: http://dx.doi.org/10.21165/el.v48i2.2276

\author{
Vinícius Gonçalves dos Santos' \\ Flaviane Romani Fernandes Svartman ${ }^{2}$
}

\section{Resumo}

Neste estudo, investigamos os eventos tonais do contorno pré-nuclear de declarativas e interrogativas neutras do português angolano do Libolo em dados de fala semiespontânea. A partir de uma análise autossegmental-métrica da entoação (LADD, 2008), conjuntamente a pressupostos da Fonologia Prosódica (NESPOR; VOGEL, 1986), observamos uma frequente associação de acentos tonais às palavras fonológicas prénucleares das sentenças. Além disso, a fronteira entre os dois sintagmas prosódicos finais em declarativas e interrogativas parciais pode ser marcada por um aparente acento frasal baixo. Concluímos, assim, que os aspectos tonais pré-nucleares do português libolense são, no geral, similares aos já descritos para outras variedades de português europeu, brasileiro, guineense e santomense, embora haja maior similaridade com as três últimas.

Palavras-chave: Libolo (Angola); fonologia; prosódia; entoação; declarativas e interrogativas neutras.

\footnotetext{
1 Universidade de São Paulo (USP), São Paulo, São Paulo, Brasil; vinicius.santos@usp.br; https://orcid.org/0000-0003-3298-1029

2 Universidade de São Paulo (USP), São Paulo, São Paulo, Brasil; flavianesvartman@usp.br; https://orcid.org/0000-0002-9941-3934
} 


\title{
Prenuclear tonal events of neutral statements and questions in Libolo Portuguese semi-spontaneous speech
}

\begin{abstract}
In this paper, we investigated the tonal events associated with the prenuclear contour of neutral statements and questions in semi-spontaneous speech data of the Angolan Portuguese as spoken in Libolo. Through an Autosegmental-Metrical approach to intonation (LADD, 2008), together with Prosodic Phonology assumptions (NESPOR; VOGEL, 1986), we observed a frequent association of pitch accents with prenuclear prosodic words in the sentences. In addition, the boundary between the two rightmost prosodic phrases of statements and yes/no questions can be marked by an apparent low phrase accent. We thus concluded that pre-nuclear tonal aspects of Libolo Portuguese are, in general, similar to those found in other varieties of European, Brazilian, BissauGuinean, and São Toméan Portuguese, even though they are more similar to the last three.
\end{abstract}

Keywords: Libolo (Angola); phonology; prosody; intonation; neutral statements and questions.

\section{Introdução ${ }^{3}$}

O Libolo é um extenso município (aprox. 9.000 km²) da Província do Kwanza-Sul, no interior de Angola, a mais de 250 km da capital Luanda. Até 2011, possuía 87.244 habitantes, dos quais cerca de $60 \%$ se concentravam em sua sede, a Comuna de Calulo (FIGUEIREDO; OLIVEIRA, 2013).

Assim como grande parte do país, o Libolo é localizado em uma área de grupos étnicos bantos. Nele são falados o quimbundo, língua banto tonal (XAVIER, 2010), e o português, língua oficial do país. O português, adquirido anteriormente como segunda língua, tornou-se atualmente a língua das gerações libolenses mais novas, que formam grande parte da população (45,5\% dos habitantes do município possuía menos de 18 anos em 2011 - FIGUEIREDO; OLIVEIRA, 2013), sobretudo nas regiões mais urbanizadas. Essa transição suscita mudanças estruturais relacionadas à sua nativização e ao contato contínuo com o quimbundo: pesquisas recentes desenvolvidas por meio do "Projeto Libolo" vêm mostrando que existem traços morfossintáticos no português libolense que são comparáveis aos encontrados no quimbundo e que são semelhantes aos descritos

30 presente trabalho foi realizado com apoio da Coordenação de Aperfeiçoamento de Pessoal de Nível Superior - Brasil (CAPES) - Código de Financiamento 001, concedido ao primeiro autor, e com apoios do Conselho Nacional de Desenvolvimento Científico e Tecnológico - Brasil (CNPq) Códigos de Financiamento 313103/2018-6 e 437021/2018-1, concedidos ao segundo autor. 
para outras variedades africanas e variedades brasileiras de português (FIGUEIREDO; OLIVEIRA, 2013; FIGUEIREDO; JORGE; OLIVEIRA, 2016; ARAÚJO; PETTER; JOSÉ, 2018; FIGUEIREDO, 2018). ${ }^{4}$

No âmbito desse projeto, um plano de trabalho visa investigar a prosódia do português falado pelos angolanos do município do Libolo (PLB), procurando estabelecer se existem traços prosódicos - potencialmente advindos do contato com o quimbundo - que distingam essa das demais variedades de português. Vinculado a esse plano mais amplo, este estudo centra-se na descrição analítica dos eventos tonais pré-nucleares de sentenças declarativas e interrogativas globais e parciais neutras do PLB. Os resultados inéditos aqui obtidos contribuem não só para a descrição das características fonéticofonológicas dessa variedade, mas também poderão servir como subsídios para uma maior compreensão linguística das variedades de português transplantadas de Portugal, como o português brasileiro.

\title{
Declarativas e interrogativas neutras
}

Declarativas e interrogativas diferenciam-se entre si quanto às suas características lexicais, sintáticas, pragmáticas e prosódicas. Esses dois tipos frásicos podem ser subdivididos em sentenças neutras e não neutras. Quando não neutras, essas sentenças exibem um constituinte ou conjunto de constituintes enfatizados/focalizados se comparado aos demais, ao passo que, quando neutras, o foco abrange toda a sentença, e não um constituinte sentencial particular - ver, por exemplo, Frota (2000). As características a seguir são algumas entre as que definem as sentenças declarativas e interrogativas globais e parciais neutras em português (BRITO; DUARTE; MATOS, 2003). ${ }^{5}$

- Sentenças declarativas neutras: apresentam ou explicam uma informação totalmente nova ao interlocutor; podem corresponder à resposta a uma pergunta do tipo "O que aconteceu?" ou a uma forma de citação (out-of-blue sentence) - ex.: 'O menino está tomando limonada'.

\begin{abstract}
4 O projeto Município do Libolo, Kwanza Sul, Angola: aspectos linguístico-educacionais, históricoculturais, antropológicos e sócio-identitários, também conhecido como Projeto Libolo, é parcialmente financiado pela Universidade de Macau e por entidades privadas filantrópicas de Angola. Trata-se de um projeto internacional e multidisciplinar cujos pesquisadores intervêm, de forma articulada, em pesquisas nas áreas de Linguística, História, Antropologia, Filologia e Ações Pedagógicas. O Projeto Libolo está devidamente patenteado pelo Centro de Investigação e Desenvolvimento (R\&DAO) da Universidade de Macau, sob o número de referência SRG011-FSH13-CGF, encontrando-se, desta forma, ao abrigo da vigente proteção de direitos autorais de propriedade intelectual designada por 'Copyright (c) 2016, R\&DAO University of Macau'. Confira http://projetolibolo.com/.
\end{abstract}

5 Adaptado de Santos e Fernandes-Svartman (a sair). 
- Interrogativas globais neutras: buscam informações novas, sendo o escopo da resposta toda a informação enunciada, uma vez que não há expectativa específica de resposta por parte do locutor; desencadeiam uma resposta do tipo sim/não; não possuem qualquer marca lexical para interrogação, sendo enunciadas com a mesma cadeia morfossintática das declarativas; distinguem-se das declarativas apenas por meios prosódicos - ex.: 'O menino está tomando limonada?'.

- Interrogativas parciais neutras: buscam informações novas, mas o escopo da resposta é uma informação específica; tal informação é identificada pela palavra interrogativa, que marca a interrogação da sentença morfossintaticamente - ex.: 'O que o menino está tomando?'.

Quanto às declarativas, há uma maior homogeneidade melódica no contorno entoacional nuclear desse tipo de sentença em variedades europeias, brasileiras, guineense e santomense de português, para as quais se atestou apenas um padrão tonal descendente ou baixo. Já interrogativas globais e parciais do português europeu e brasileiro apresentam contornos entoacionais nucleares mais heterogêneos, particularmente as globais, sendo atestados padrões tonais ascendentes e ascendentes-descendentes de alinhamentos variados (FROTA, 2000, 2014; TENANI, 2002; FERNANDES, 2007; MORAES, 2008; SERRA, 2009; CRUZ, 2013; FROTA et al., 2015; SANTOS, 2015; CASTELO, 2016; ROSIGNOLI, 2017; BRAGA, 2018; FERNANDES-SVARTMAN et al., a sair; entre outros).

No PLB, os contornos entoacionais nucleares desses três tipos frásicos são semelhantes aos que foram descritos para outras variedades de português (SANTOS; FERNANDESSVARTMAN, a sair). Para as declarativas são encontrados os dois padrões já mencionados: um contorno nuclear descendente $H+L * L \%$ majoritário e um padrão baixo $L * L \%$ menos frequente. Quando fraseadas em dois sintagmas entoacionais, predominantemente (S) (VO), seu contorno nuclear não final é ascendente $L+H^{*} H \%$. As demais variedades de português empregam a mesma estratégia para a caracterização desse sintagma: a pausa e o tom de fronteira alto. Já as interrogativas globais apresentam um contorno nuclear ascendente ou ascendente-descendente, $L^{*} H \%$ e $L+H^{*} L \%$, que também caracterizam esse tipo frásico em outras variedades de português. Portanto, a diferença entre declarativas e interrogativas globais (que são vistas como a contraparte interrogativa daquelas) é codificada prosodicamente, na língua, por acentos tonais e tons de fronteiras contrastivos. Por sua vez, as interrogativas parciais exibem predominantemente um contorno nuclear descendente $H_{+} L^{*} L \%$, semelhante ao da declarativa, assim como ocorre no português europeu e brasileiro. Logo, a diferença entre interrogativas parciais e declarativas é transmitida morfossintaticamente, usando-se a palavra interrogativa. Contudo, encontram-se também, em menor frequência, os padrões ascendentes L* $H \%$ e $L+H^{*} L \%$, como os das interrogativas globais. Em tais casos, os enunciados são marcados para interrogação simultaneamente por marcas sintáticas e prosódicas, de modo paralelo ao que já foi observado no português brasileiro e europeu. 
Conforme descrevemos no decorrer deste artigo, o contorno pré-nuclear do PLB é, no geral, similar ao de outras variedades de português europeu, brasileiro, guineense e santomense, embora haja maior similaridade com as três últimas.

\section{Pressupostos teóricos}

A análise entoacional deste estudo foi realizada com base na Fonologia Entoacional Autossegmental-Métrica (PIERREHUMBERT, 1980; LADD, 2008 [1996]; JUN, 2005, 2014; FROTA; PRIETO, 2015; entre outros), para a qual a variação melódica da fala corresponde a eventos tonais, que possuem somente dois alvos de altura: baixo - $\mathrm{L}$ (low) e alto $-\mathrm{H}$ (high). Em português, os eventos tonais relevantes para a descrição das propriedades entoacionais da língua são os acentos tonais, os acentos frasais e os tons de fronteira (FROTA, 2000, 2014; TENANI, 2002; FERNANDES, 2007; CRUZ, 2013; FROTA et al., 2015; SANTOS, 2015; BRAGA, 2018; entre outros).

$\mathrm{O}$ acento tonal é a variação melódica associada a sílabas que carregam acento lexical, podendo ser baixo $\left(L^{*}\right)$, alto $\left(H^{*}\right)$, descendente $\left(H^{*}+L, H+L^{*}\right)$ ou ascendente $\left(L+H^{*}\right.$, $\left.L^{*}+H\right)$. Convencionalmente, o tom alinhado à sílaba tônica é indicado pelo asterisco e a combinação de dois tons é indicada por "+". Já o acento frasal e o tom de fronteira são variações melódicas realizadas em fronteiras de domínios prosódicos. O primeiro associase a sintagmas fonológicos, sendo baixo $\left(\mathrm{L}^{-}\right)$ou alto $\left(\mathrm{H}^{-}\right)$, e o segundo, a sintagmas entoacionais, podendo ser baixo (L\%), alto (H\%), descendente (HL\%) ou ascendente (LH\%).

Os domínios prosódicos são unidades fonológicas hierarquicamente estruturadas e resultantes da segmentação do contínuo da fala. Eles fornecem as relações de constituição e proeminência métrica que regem a associação de eventos tonais à cadeia segmental (HAYES; LAHIRI, 1991; FROTA, 2000; TENANI, 2002; entre outros). A hierarquia prosódica do português aqui adotada (FROTA, 2000, 2014; TENANI, 2002; VIGÁRIO, 2003, 2010), firmada nos pressupostos teóricos da Fonologia Prosódica (NESPOR; VOGEL, 1986), é composta pelos seguintes domínios prosódicos: sílaba $\left(S_{Y L}\right)$, pé $\left(F_{T}\right)$, palavra fonológica $(P W)$, grupo de palavras fonológicas (PWG), sintagma fonológico $\left(P_{h} P\right)$, sintagma entoacional (IP) e enunciado fonológico (U). Nessa hierarquia, os domínios prosódicos de maior relevância para nossa análise são três: $P W$, PhP e IP.

PW é o domínio prosódico que abrange apenas um único acento lexical, de modo que clíticos devem ser incorporados ou adjungidos à palavra acentuada adjacente (VIGÁRIO, 2003). Já PhP é o domínio prosódico que engloba um núcleo lexical, os itens funcionais à sua esquerda (lado não recursivo em português) e, opcionalmente, o sintagma não ramificado e complemento de tal núcleo lexical (FROTA, 2000). Por sua vez, IP é o domínio prosódico que circunscreve uma sequência de PhPs, que detém um contorno entoacional definido e cujas fronteiras são posições de inserção de pausas gramaticais. 
Em sentenças neutras do português, o elemento de maior proeminência relativa de IP é a $P W$ mais à direita. Essa PW, referida como "nuclear", carrega o contorno entoacional nuclear; as demais PWs de IP, referidas como "pré-nucleares", são elementos de menor proeminência relativa e compõem o contorno entoacional pré-nuclear da sentença (FROTA, 2000; TENANI, 2002). Como já mencionado, este trabalho dedica-se aos eventos tonais que compõem esse último tipo de contorno.

\section{Corpus e procedimentos metodológicos}

Os dados de análise foram obtidos por meio do Discourse Completion Test (DCT) do projeto InAPoP. ${ }^{6}$ Nesse teste, o entrevistador apresenta oralmente ao participante uma série de situações cotidianas, eventualmente com auxílio de imagens. O participante, então, imaginando-se em cada situação, produz um determinado enunciado, permitindo que se obtenha, de forma semiespontânea, sentenças com significados pragmáticos variados (declarativas e interrogativas neutras e não neutras, vocativos e imperativos).

As situações das versões pré-existentes do DCT em português brasileiro e europeu foram adaptadas ao PLB (com auxílio de falantes nativos) durante uma pesquisa de campo realizada no âmbito do "Projeto Libolo". Em campo, o teste aleatorizado foi aplicado de três a seis vezes a quatro participantes libolenses: uma mulher ( $\mathrm{MJ}$ ) e três homens (SF, AJ, JD) de mesma faixa etária (23 a 31 anos), bilíngues em português e quimbundo, escolarizados (com ensino básico angolano completo) e naturais de Calulo, sede do município do Libolo. A performance dos participantes foi registrada por meio de um microfone de lapela Sennheiser EW122-P G3 e um gravador Marantz PMD-661 (44 kHz, .wav, monofônico, 16 bits, 705-1411 Kbps).

Para este estudo, foram selecionadas as respostas para sete situações adaptadas (ver Quadro 1), entre as quais descartou-se as respostas que apresentam hesitações (como repetições e interrupções) ou ênfase/foco, tendo sido considerado para a análise um total de 159 sentenças [ 7 situações $\times 4$ falantes $\times 3-6$ repetições]. ${ }^{7}$

\footnotetext{
60 InAPoP, Interactive Atlas of the Prosody of Portuguese (http://labfon.letras.ulisboa.pt/InAPoP/), é um projeto sediado na Universidade de Lisboa, sob coordenação da Profa. Dra. Sónia Frota, que visa o mapeamento da prosódia (fraseamento, entoação, ritmo) de variedades europeias, brasileiras e africanas do português, e a criação de um atlas interativo da prosódia do português com diversos recursos resultantes dos estudos realizados.
}

7 Duas situações não foram consideradas neste estudo pelo fato de produzirem enunciados declarativos neutros ('Casaram') e interrogativos globais neutros ('Choveu?') contendo apenas uma palavra prosódica. 
Quadro 1. Situações para a produção de declarativas e interrogativas neutras no PLB ${ }^{8}$

\begin{tabular}{|c|c|c|}
\hline Sentença neutra & Situação & $\begin{array}{l}\text { Resposta esperada } \\
\text { possível }\end{array}$ \\
\hline \multirow[t]{3}{*}{ Declarativa } & Olha pro desenho e diz o que ele faz. & $\begin{array}{l}\text { Está tomando uma } \\
\text { limonada. }\end{array}$ \\
\hline & Olha pro desenho e diz o que ela faz. & Ela toma uma limonada. \\
\hline & $\begin{array}{l}\text { Este aí na fotografia é o galã da novela. } \\
\text { Diz que o galã anda de carro. }\end{array}$ & O galã anda de carro. \\
\hline $\begin{array}{l}\text { Interrogativa } \\
\text { global }\end{array}$ & $\begin{array}{l}\text { Você entra numa cantina e pergunta ao } \\
\text { vendedor se tem ginguba. }{ }^{9}\end{array}$ & Tem ginguba? \\
\hline \multirow{3}{*}{$\begin{array}{l}\text { Interrogativa } \\
\text { parcial }\end{array}$} & Pergunta que horas são. & Que horas são? \\
\hline & $\begin{array}{l}\text { Você precisa comprar um presente pra } \\
\text { uma pessoa que você não conhece } \\
\text { muito bem. Então, você pede ajuda pro } \\
\text { K. Pergunta pra ele o que lhe daria. }\end{array}$ & O que lhe darias? \\
\hline & $\begin{array}{l}\text { Você me viu conversando por muito } \\
\text { tempo com o } K \text {. Então, você me pergunta } \\
\text { o que ele me contava. }\end{array}$ & O que te contava? \\
\hline
\end{tabular}

Fonte: Elaboração própria.

A análise dos dados foi feita por meio da transcrição prosódica, com base no sistema de anotações prosódicas P_ToBI (Portuguese Tones and Break Indices), ${ }^{10}$ a partir do oscilograma, espectrograma e curva de $F_{0}$ (frequência fundamental) obtidos para cada enunciado no software Praat (BOERSMA; WEENINK, 2018). O P_ToBI possui as seguintes camadas de anotação:

- Tons (tones) - nessa camada, os eventos tonais são transcritos fonologicamente; são indicados aqui somente os eventos tonais associados ao contorno entoacional pré-nuclear.

8 Nas seguintes situações, uma imagem é mostrada ao participante em tela de computador: (1) um menino tomando limonada; (2) uma mulher tomando limonada; (3) um homem dirigindo um carro.

9 Ginguba é sinônimo de amendoim.

10 http://labfon.letras.ulisboa.pt/InAPoP/P-ToBI/ 
- Ortografia (ortography) - nessa camada, as palavras da sentença são transcritas ortograficamente.

- Fraseamento (BI, break indices) - nessa camada, índices numéricos de 0 a 4 indicam o maior grau de juntura entre os constituintes da sentença de acordo com o seu fraseamento em domínios prosódicos ( $0=$ clítico, $1=P W, 2=P W G, 3=P h P, 4=I P)$. Entre os índices, apenas 1, 3 e 4 são aqui indicados.

\section{Resultados}

Em números absolutos, as declarativas do corpus possuem, ao todo, 170 PWs prénucleares. Já as interrogativas globais contêm 18 PWs pré-nucleares e as interrogativas parciais, 79.

Cada sentença possui entre uma e quatro PWs pré-nucleares $\left(P W_{P N}\right)$, conforme se observa nos exemplos dados em (1) para as declarativas, em (2) para as interrogativas globais e em (3) para as interrogativas parciais. Nos exemplos, as PWs pré-nucleares encontram-se em negrito. Quando a sentença é mapeada em dois IPS, conforme visto no exemplo (4), o contorno entoacional associado à PW mais à direita do primeiro IP é também nuclear e, portanto, não considerado parte do contorno pré-nuclear. ${ }^{11}$

$$
\begin{aligned}
& 1 \mathrm{PW}_{\mathrm{PN}}:(\text { Tomando })_{\mathrm{PW}}(\text { limonada. })_{\mathrm{PW}} \\
& 2 \mathrm{PW}_{\mathrm{PN}}:(\text { O galã })_{\mathrm{PW}}(\text { anda })_{\mathrm{PW}}(\text { de carro. })_{\mathrm{PW}} \\
& 3 \mathrm{PW}_{\mathrm{PN}}:(\text { Ela })_{\mathrm{PW}}(\text { está })_{\mathrm{PW}}(\text { a tomar })_{\mathrm{PW}}(\text { limonada. })_{\mathrm{PW}} \\
& 4 \mathrm{PW}_{\mathrm{PN}}:(\text { Ela })_{\mathrm{PW}}(\text { está })_{\mathrm{PW}}(\text { a tomar })_{\mathrm{PW}}(\text { sumo })_{\mathrm{PW}}(\text { de limão. })_{\mathrm{PW}}
\end{aligned}
$$

(2) $1 \mathrm{PW}_{\mathrm{PN}}:(\text { Tem })_{\mathrm{PW}}(\text { ginguba? })_{\mathrm{PW}}$

(3) 1 PW $:$ (Que horas $)_{\mathrm{PW}}(\text { (são? })_{\mathrm{PW}}$

$$
\begin{aligned}
& 2 \mathrm{PW}_{\mathrm{PN}}:(\mathbf{0} \text { que })_{\mathrm{PW}}(\text { que ele })_{\mathrm{PW}}(\text { te contava? })_{\mathrm{PW}} \\
& 3 \mathrm{PW}_{\mathrm{PN}}:(\mathbf{0} \text { que })_{\mathrm{PW}}(\text { que ela })_{\mathrm{PW}}(\text { tava })_{\mathrm{PW}}(\text { te contando? })_{\mathrm{PW}}
\end{aligned}
$$

(4) $2 \mathrm{PW}_{\mathrm{PN}}: \llbracket(\mathbf{0} \text { ator })_{\mathrm{PW}}(\text { de novela })_{\mathrm{PW}} \rrbracket_{I P} \llbracket(\text { anda })_{\mathrm{PW}}(\text { de carro. })_{\mathrm{PW}} \rrbracket_{I P}$

11 Em estudo dedicado ao contorno entoacional nuclear do PLB (SANTOS; FERNANDESSVARTMAN, a sair), observamos que as sentenças mapeadas em dois IPs ocorrem apenas entre as declarativas neutras, exibem majoritariamente o padrão de fraseamento que separa o sujeito sentencial do verbo e do objeto - ou seja, $(\mathrm{S})_{\mathbb{P}}(\mathrm{VO})_{\mathbb{P}}$ - e não são frequentes, ocorrendo em apenas $22 \%$ do total de declarativas analisadas. 
Associados aos domínios prosódicos que os elementos dessas sentenças formam, encontram-se acentos tonais e acentos frasais, que são descritos nas seções a seguir.

\section{Distribuição dos acentos tonais}

A partir da análise dos dados, é possível observar que tanto em declarativas neutras quanto em interrogativas globais e parciais neutras é frequente a associação de um acento tonal a cada PW pré-nuclear. Do total de PWs pré-nucleares que formam as sentenças declarativas do corpus, $84,3 \%$ portam um acento tonal. Já para as interrogativas globais e parciais, $94,4 \%$ e $84,8 \%$ do total de suas $P W$ s pré-nucleares, respectivamente, portam um acento tonal. Os resultados para a distribuição de acentos tonais são apresentados nas Tabelas 1, 2 e 3, nas quais é fornecido o número de acentos tonais realizados pelo número de PWs, sendo organizados pela quantidade de PWs pré-nucleares das sentenças.

Tabela 1. Distribuição de acentos tonais em declarativas

\begin{tabular}{|c|c|c|c|c|}
\hline & $1 \mathrm{PW}_{\mathrm{PN}}$ & $2 \mathrm{PW}_{\mathrm{PN}}$ & $3 \mathrm{PW}_{\mathrm{PN}}$ & $4 \mathrm{PW}_{\mathrm{PN}}$ \\
\hline MJ & $4 / 4$ & $6 / 8$ & $9 / 12$ & $3 / 4$ \\
\hline SF & $4 / 4$ & $33 / 36$ & $6 / 6$ & - \\
\hline AJ & $1 / 1$ & $14 / 16$ & $11 / 15$ & $11 / 20$ \\
\hline JD & $4 / 4$ & $26 / 28$ & $6 / 6$ & $7 / 8$ \\
\hline \multirow{2}{*}{ Total } & 13/13 (100\%) & 79/88 (89,8\%) & $32 / 39(82,1 \%)$ & 21/32 (65,6\%) \\
\hline & \multicolumn{4}{|c|}{$145 / 172(84,3 \%)$} \\
\hline
\end{tabular}

Fonte: Elaboração própria.

Tabela 2. Distribuição de acentos tonais em interrogativas globais

\begin{tabular}{l|c}
\hline & ${\mathbf{1 ~} \mathbf{W}_{\mathbf{P N}}}$ \\
\hline $\mathrm{MJ}$ & $3 / 3$ \\
\hline $\mathrm{SF}$ & $6 / 6$ \\
\hline $\mathrm{AJ}$ & $3 / 4$ \\
\hline $\mathrm{JD}$ & $5 / 5$ \\
\hline Total & $17 / 18(94,4 \%)$ \\
\hline
\end{tabular}

Fonte: Elaboração própria. 
Tabela 3. Distribuição de acentos tonais em interrogativas parciais

\begin{tabular}{|c|c|c|c|}
\hline & $1 \mathrm{PW}_{\mathrm{PN}}$ & $2 \mathrm{PW}_{\mathrm{PN}}$ & $3 \mathrm{PW}_{\mathrm{PN}}$ \\
\hline MJ & $8 / 8$ & $2 / 2$ & $1 / 3$ \\
\hline SF & $20 / 20$ & - & $2 / 3$ \\
\hline AJ & $9 / 16$ & $1 / 2$ & - \\
\hline JD & 19/19 & $5 / 6$ & - \\
\hline \multirow{2}{*}{ Total } & 56/63 (88,9\%) & $8 / 10(80 \%)$ & $3 / 6(50 \%)$ \\
\hline & \multicolumn{3}{|c|}{$67 / 79(84,8 \%)$} \\
\hline
\end{tabular}

Fonte: Elaboração própria.

Podemos observar, a partir dos dados das declarativas, que a porcentagem de PWs sem acento tonal tende a diminuir conforme a sentença se torna mais extensa em número de PWs. Quando há apenas uma PW pré-nuclear, ela porta categoricamente um acento tonal, o que é semelhante ao que se observa nas interrogativas também: embora a densidade tonal em sentenças com apenas uma PW pré-nuclear nos dois tipos de interrogativas não seja $100 \%$ (mas $84,3 \%$ e $84,8 \%$ para as globais e parciais, respectivamente), isso se deve aos dados do falante $A J$, que apresenta a maior taxa de elocução média ( $M J=0,170$; $\mathrm{JD}=0,166 ; \mathrm{SF}=0,162 ; \mathrm{AJ}=0,140$ ), calculada pela duração do enunciado dividido pelo seu número de sílabas. Para os demais falantes, com menor taxa de elocução, a atribuição do acento tonal a essa PW ocorre em todos os casos.

Embora o baixo número de sílabas átonas entre as sílabas tônicas possa ser um importante fator para a distribuição dos acentos tonais, não se pode descartar a relevância da posição da PW também. De todas as PWs sem acento tonal do corpus, 47,5\% ( $n=19 / 40)$ são cabeças de PhP (isto é, a única PW ou a mais à direita desse domínio quando disponível), conforme exemplificado em (5) para (anda) ${ }_{P W^{*}}$. No entanto, se considerarmos que, diferentemente do português europeu (VIGÁRIO, 1998), uma sequência de proclítico e PW não conta para ramificação fonológica e que, portanto, PhPs podem se reestruturar com PhPs subsequentes formados por uma PW contendo um proclítico, conforme ilustrado em (6), apenas 10\% $(n=4 / 40)$ das PWs sem acento tonal ainda seriam cabeças de PhP; todas elas constantes, novamente, dos dados do falante AJ.

$$
\begin{aligned}
& \llbracket\left[(\text { O galã })_{\mathrm{PW}}\right]_{\mathrm{PhP}}\left[(\text { anda })_{\mathrm{PW}}\right]_{\mathrm{PhP}}\left[(\text { de carro })_{\mathrm{PW}}\right]_{\mathrm{PhP}} \rrbracket_{I P} \\
& \begin{array}{lll}
T^{*} & T^{*} & L \%
\end{array}
\end{aligned}
$$




$$
\llbracket\left[(\text { O galã })_{\mathrm{PW}}\right]_{\mathrm{PhP}}\left[(\text { anda })_{\mathrm{PW}}(\text { de carro })_{\mathrm{PW}}\right]_{\mathrm{PhP}} \rrbracket_{\mathrm{IP}}
$$

$$
T^{\star} \quad T^{\star} \quad L \%
$$

Isso significa que, assim como já se observou em outras línguas (NESPOR; VOGEL, 1986), a constituência prosódica do enunciado e a taxa de elocução podem juntas também ser um fator regulador de atribuição de acentos tonais ao contorno pré-nuclear de tais sentenças no PLB.

Ademais, muito embora as sentenças do corpus não possam estabelecer rigorosamente as propriedades de distribuição tonal do PLB - visto que são formadas por poucas PWs e não possuem um controle sistemático de sua constituência sintático-prosódica, posto que são semiespontâneas -, elas podem consistir em um indicativo da alta associação tonal do sistema prosódico da variedade, conforme também já indicado por Santos e Braga (2017, p. 84) para sentenças de corpora de outros estilos discursivos do PLB em processo de análise. Os autores ainda observam que a variação na distribuição dos acentos tonais é uma propriedade prosódica que divide as variedades do português em ultramarinas (brasileiras, guineense e santomense) e não ultramarinas (europeias): (i) no português europeu (PE) lisboeta, a presença de eventos tonais no contorno prénuclear é rara, sendo encontrado apenas um acento tonal ou tom de fronteira inicial em IP (e.g. FROTA, 2000, 2014); (ii) no PE de Braga, Alentejo e Algarve e nas variedades do português brasileiro (PB), toda PW cabeça de PhP porta um acento tonal (e.g. TENANI, 2002; VIGÁRIO; FROTA, 2003; CRUZ, 2013); (iii) ademais, no PB, além desse acento tonal obrigatório, encontram-se também acentos tonais associados a quase todas as PWs não cabeça de PhP (e.g. TENANI, 2002; FERNANDES, 2007). ${ }^{12}$ Em nossos dados, a proporção entre o número de acentos tonais realizados e o de PWs existentes no contorno prénuclear é acima de $84 \%$ para todos os tipos frásicos, reforçando a inclusão do PLB ao grupo de variedades ultramarinas citadas quanto a essa propriedade prosódica (para as quais se reportam densidades tonais acima de $80 \%$ ) em detrimento das não ultramarinas (para as quais se reportam densidades tonais abaixo de 80\%).

\section{Tipos de acentos tonais}

De modo geral, há uma preferência por acentos tonais ascendentes $L^{+} H^{\star}$ e $L^{*}+H$ nas declarativas, que formam juntos 69,3\% ( $n=99 / 145)$ dos acentos tonais realizados (ver Tabela 4). Entre eles, o primeiro é o mais frequente e comum a todos os falantes e o segundo deve a sua alta frequência aos dados do falante JD. $\mathrm{O}$ acento tonal $\mathrm{L}+\mathrm{H}^{*}$ representa uma ascendência da curva de $F_{0}$ que se inicia no onset da sílaba tônica e termina em seu offset, seguido frequentemente por um declínio da curva. O acento tonal

12 Para detalhes acerca das densidades tonais nas diferentes variedades de português europeu e brasileiro, confira a seção 5 do artigo de Santos e Braga (2017) e as referências nela citadas. 
$L^{*}+\mathrm{H}$ também representa uma ascendência tonal. No entanto, essa ascendência inicia-se na sílaba tônica e seu pico está localizado na postônica.

É também frequente, totalizando 20\% $(n=29 / 145)$ das ocorrências, o acento tonal $H^{\star}$, que representa uma relativa estabilidade alta de F0 ao longo da sílaba tônica. Para todos os falantes, esse acento tonal ocorre associado exclusivamente à sílaba que está em início

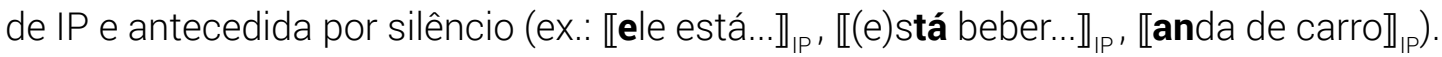

Há, ainda, em menor frequência, os acentos tonais $H+! H^{*}$ e $L^{*}$, que somam apenas $11,7 \%$ $(n=17 / 145)$ das ocorrências. $O$ acento tonal $L *$ representa uma relativa estabilidade baixa de $F_{0}$ ao longo da sílaba tônica e é encontrado nos dados de todos os falantes. Já o acento tonal $\mathrm{H}+\mathrm{H}^{*}$ representa uma relativa estabilidade alta (ou, por vezes, levemente aclive) de $F_{0}$ ao longo da sílaba tônica e que é precedida de um nível mais alto de $F_{0} e$ sucedida por um declínio de $F_{0}$. Esse acento tonal pertence exclusivamente aos dados do falante SF e ocorre somente no seguinte contexto: associado à segunda PW de uma sequência de duas PWs que portam acento tonal e cujas sílabas tônicas são separadas por apenas uma átona - ex.: (está) $)_{\mathrm{PW}}\left(\right.$ tomando) ${ }_{\mathrm{PW}}$. É possível que o movimento tonal que indicamos por $\mathrm{H}+! \mathrm{H}^{*}$ seja uma realização de $\mathrm{L}+\mathrm{H}^{\star}$ em tal contexto - no qual o tom baixo é marcado pela abrupta mudança do nível tonal, mas a ascendência não é pronunciada e nem o pico é evidente -, já que $L+H^{*}$ também pode ocorrer nessa mesma posição.

Tabela 4. Configuração dos acentos tonais pré-nucleares das declarativas

\begin{tabular}{c|c|c|c|c|c}
\hline & $\mathbf{H + !}^{*}$ & $\mathbf{L}^{*}$ & $\mathbf{H}^{\boldsymbol{*}}$ & $\mathbf{L}^{*}+\mathbf{H}$ & $\mathbf{L + H}^{*}$ \\
\hline $\mathrm{MJ}$ & - & 2 & 1 & 7 & 12 \\
\hline $\mathrm{SF}$ & 6 & 1 & 9 & - & 27 \\
\hline AJ & - & 5 & 13 & 2 & 17 \\
\hline JD & - & 3 & 6 & 24 & 10 \\
\hline \multirow{2}{*}{ Total } & 6 & $11(7,6 \%)$ & $29(20 \%)$ & $33(22,8 \%)$ & $66(45,5 \%)$ \\
\cline { 2 - 6 } & $(4,1 \%)$ & \multicolumn{5}{|c}{145} \\
\hline
\end{tabular}

Fonte: Elaboração própria.

Em interrogativas globais, foram atestados os acentos tonais $H^{*} e \mathrm{~L}+\mathrm{H}^{*}$, já observados nas declarativas, que apresentam frequências relativamente próximas (ver Tabela 5). À exceção de JD, apenas um entre os dois acentos tonais é realizado para todos os demais falantes. Além disso, assim como nas declarativas, nessa interrogativa, $\mathrm{H}^{*}$ está associado a uma sílaba tônica em início de IP e antecedida por silêncio, isto é, 【tem ginguba】IP. Já em interrogativas parciais, foram atestados acentos majoritariamente altos $H^{\star}(65,7 \%)$, 
que ocorrem somente quando são o primeiro acento tonal de IP, e os ascendentes $L+H^{*}$ e $L^{*}+H$ (que somam juntos $34,3 \%$ das ocorrências) (ver Tabela 6), todos também já atestados nos outros dois tipos frásicos.

Tabela 5. Configuração dos acentos tonais pré-nucleares das interrogativas globais

\begin{tabular}{c|c|c}
\hline & $\mathbf{H}^{\mathbf{}}$ & $\mathbf{L + \mathbf { H } ^ { * }}$ \\
\hline \multirow{2}{*}{ MJ } & 3 & - \\
\hline SF & - & 6 \\
\hline AJ & 3 & - \\
\hline \multirow{2}{*}{ JD } & 2 & 3 \\
\hline \multirow{2}{*}{ Total } & $8 / 17(47,1 \%)$ & $9 / 17(52,9 \%)$ \\
\cline { 2 - 3 } & \multicolumn{2}{|c}{17} \\
\hline
\end{tabular}

Fonte: Elaboração própria.

Tabela 6. Configuração dos acentos tonais pré-nucleares das interrogativas parciais

\begin{tabular}{c|c|c|c}
\hline & $\mathbf{L}^{*}+\mathbf{H}$ & $\mathbf{L + H}^{*}$ & $\mathbf{H}^{*}$ \\
\hline MJ & 3 & 4 & 4 \\
\hline SF & - & 4 & 18 \\
\hline AJ & - & 1 & 9 \\
\hline JD & - & 11 & 13 \\
\hline \multirow{2}{*}{ Total } & $3(4,5 \%)$ & $20(29,8 \%)$ & $44(65,7 \%)$ \\
\cline { 2 - 4 } & \multicolumn{3}{|c}{67} \\
\hline
\end{tabular}

Fonte: Elaboração própria.

Ademais, em muitas interrogativas do corpus, sejam globais ou parciais, percebemos uma maior gama de variação tonal se comparada à gama das declarativas. Observe, por exemplo, as sentenças das figuras aqui fornecidas. Nelas, a diferença média entre o tom $\mathrm{H}$ de um acento tonal pré-nuclear e o tom $\mathrm{L}$ do evento tonal subsequente é de 44,1 Hz para as declarativas (Figuras 1 e 4a); já para as interrogativas globais (Figura 2), essa diferença entre tons é de 131,8 Hz e para as interrogativas parciais (Figuras 3 e 4b), de $115,9 \mathrm{~Hz}$. Logo, a investigação sistemática do escalonamento tonal em todas as sentenças do corpus poderá indicar se há, de fato, diferenças significativas na altura tonal entre os tipos frásicos. 
Embora existam tipos variados de acentos tonais no contorno pré-nuclear das declarativas e das interrogativas, a partir da descrição aqui realizada, há evidência para reconhecer que (i) a associação de cada tipo de acento tonal parece não ser aleatória, visto que $H^{*}$ e $\mathrm{H}+$ ! $\mathrm{H}^{*}$, por exemplo, ocorrem em posições determinadas, e que (ii) os acentos tonais ascendentes, sejam eles $L+H^{*}$ ou $L^{*}+H$, juntamente com $H^{*}$, são os representativos do contorno pré-nuclear devido à sua alta frequência.

As Figuras 1, 2 e 3 ilustram características do contorno pré-nuclear das declarativas, interrogativas parciais e interrogativas globais respectivamente, nas quais é possível observar a frequente associação de acentos tonais a cada PW da sentença, bem como os acentos tonais predominantes $\left(L+H^{*}, L^{*}+H, H^{*}\right)$ e a gama de variação tonal maior em certas interrogativas em detrimento das declarativas.
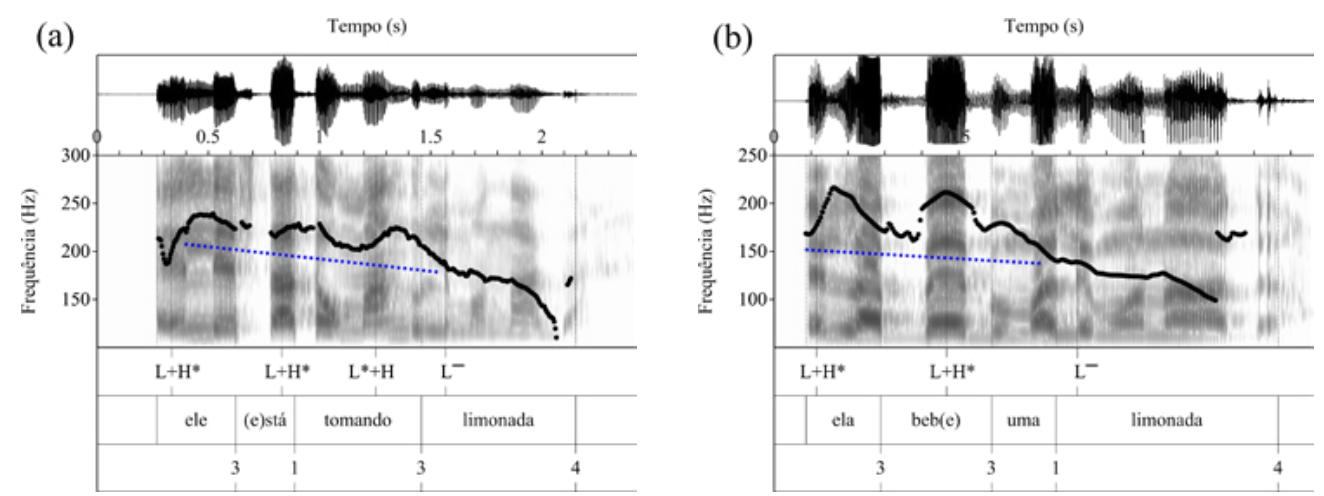

Figura 1. Declarativas neutras 'Ele está tomando limonada' e 'Ela bebe uma limonada' produzidas por MJ e SF, respectivamente

Fonte: Elaboração própria.
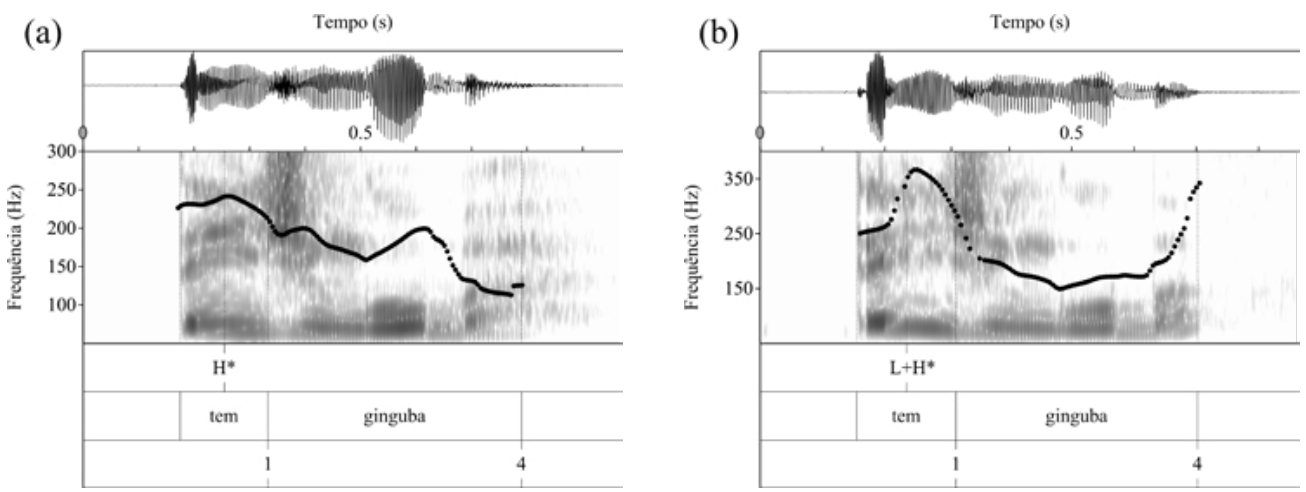

Figura 2. Interrogativas globais neutras 'Tem ginguba?' produzidas por JD

Fonte: Elaboração própria. 

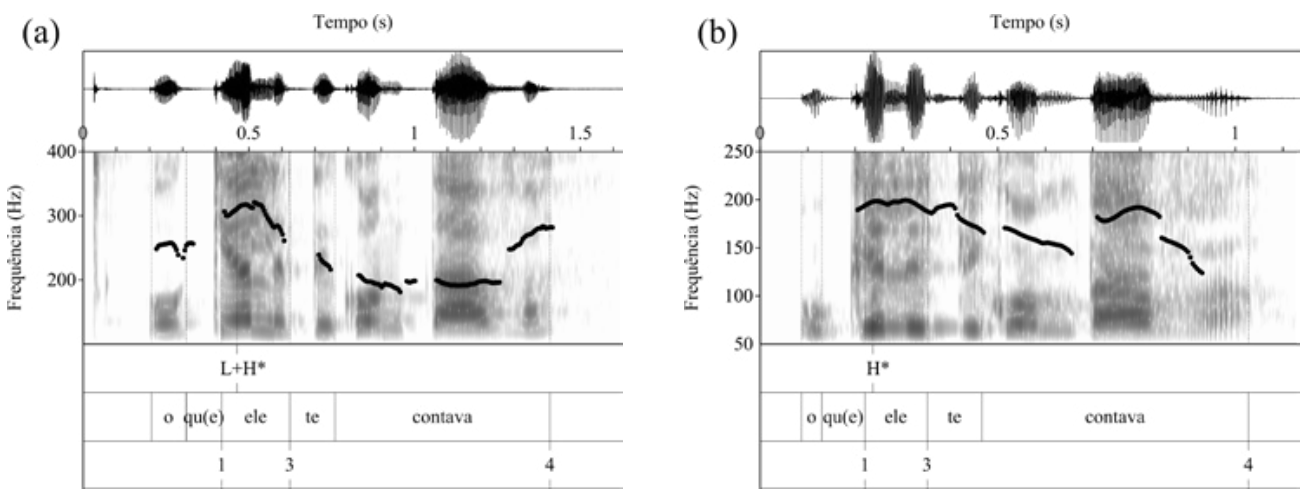

Figura 3. Interrogativas parciais neutras 'O que ele te contava?' produzidas por MJ e AJ, respectivamente

Fonte: Elaboração própria.

\section{Acentos frasais}

Encontramos, nos dados, movimentos tonais realizados no contorno pré-nuclear de declarativas e interrogativas parciais que podem ser interpretados como acentos frasais de tom baixo, indicados por $\mathrm{L}^{-}$(ver Figuras 1 e 4). Esses supostos acentos frasais estão associados à fronteira que delimita as duas últimas PWs das sentenças, as quais putativamente formam PhPs independentes. O movimento tonal é encontrado nas declarativas de todos os falantes, ocorrendo em $51,2 \%$ do total desse tipo frásico no corpus (ver Tabela 7). No entanto, para interrogativas parciais, é encontrado somente nos dados de dois falantes (SF, JD), ocorrendo em $20 \%$ desse tipo frásico.

Tabela 7. Distribuição dos potenciais acentos frasais

\begin{tabular}{c|c|c}
\hline & Declarativa & Interrogativa parcial \\
\hline \multirow{2}{*}{ MJ } & $7 / 12$ & $0 / 10$ \\
\hline SF & $21 / 24$ & $8 / 21$ \\
\hline AJ & $4 / 19$ & $0 / 17$ \\
\hline \multirow{2}{*}{ JD } & $9 / 25$ & $6 / 22$ \\
\hline \multirow{2}{*}{ Total } & $41 / 80(51,2 \%)$ & $14 / 70(20 \%)$ \\
\cline { 2 - 3 } & \multicolumn{2}{|c}{55} \\
\hline
\end{tabular}

Fonte: Elaboração própria. 
Nos casos em que há somente uma sílaba pretônica na PW nuclear - ex.: (anda) ${ }_{\mathrm{PW}}$ (de carro) ${ }_{\mathrm{PW}}$-, há um abrupto abaixamento da curva de $\mathrm{F}_{0}$ no limite das duas PWs (ver Figura 4a). Já nos casos em que há mais de uma sílaba pretônica na PW nuclear - ex.: (tomando) ${ }_{\mathrm{PW}}\left(\right.$ limonada) ${ }_{\mathrm{PW}}$-, há uma cessão do declínio da curva de $\mathrm{F}_{0}$ e manutenção da altura da curva até a realização do acento tonal nuclear (ver Figura 1a). A curva de $F_{0}$ atinge seu vale na primeira sílaba pretônica da palavra nesses casos. Se existirem itens funcionais clíticos relacionados a ela, embora o vale incida frequentemente no clítico (Ihe, te, de) (ver Figura 4), na presença da palavra 'uma', o vale ocorre na primeira sílaba do item lexical, após esse item funcional (ver Figura 1b). Esse último fato pode sugerir que esses acentos frasais em potencial não marquem limites de PhPs, mas os de domínios inferiores na hierarquia prosódica, visto que 'uma' não é mapeado em um PhP independente de 'limonada' segundo o algoritmo de formação desse domínio prosódico.

A marcação de fronteiras de domínios prosódicos inferiores a PhP (ou domínio equivalente, conforme a análise), como a PW, é atestada em várias línguas, mas nenhuma românica (JUN, 2005, 2014). Em português, acentos frasais de tom baixo não são exclusivos dos nossos dados. Eles também são atestados em variedades de PB, PE, português guineense (PGB) e santomense (PST), embora sempre com referência ao domínio de PhP. No PB paulista, podem se associar à fronteira direita de PhPs contendo elementos focalizados em declarativas e interrogativas (FERNANDES, 2007; ROSIGNOLI, 2017). No PE alentejano, são associados opcionalmente à fronteira esquerda do PhP cabeça de IP em diversos tipos frásicos (CRUZ, 2013). Já no PGB e no PST, são encontrados delimitando fronteiras de PhPs ao longo de declarativas, não sendo claro o fator que condiciona essa associação (SANTOS, 2015; BRAGA, 2018). Dado que em corpora de leitura do PLB aqui não contemplados encontramos acentos frasais presumidos nos limites de constituintes ocupando várias posições da sentença, esse evento tonal aproxima-se mais aos acentos frasais do PGB e do PST do que aos do PB (relacionados exclusivamente a foco) e aos do PE (relacionados a uma determinada posição em IP).

Contudo, não se pode desconsiderar que o abaixamento abrupto e a interrupção do declínio da curva de $F_{0}$ nos dados do PLB possam estar relacionados não à presença de um acento frasal, mas à realização do contorno entoacional nuclear abaixo da linha de referência dos tons $L$ pré-nucleares não finais, ${ }^{13}$ uma característica frequentemente encontrada nas declarativas e interrogativas parciais de acento tonal nuclear $\mathrm{H}+\mathrm{L}^{*}$ que nem sempre é concomitante à presença de $L^{-}$. Os tons $L$ e $H$ de um contorno entoacional alinham-se sobre uma linha abstrata denominada de linhas de referência dos tons $L e$ dos tons $\mathrm{H}$, tendencialmente declinantes, relativamente paralelas e variáveis para cada falante (VIGÁRIO, 1998). Nas Figuras 1 e 4, a linha de referência L é indicada por um tracejado. Diversos estudos reportam processos de mudança de registro e variação de

13 Nos corpora de sentenças lidas não tratados aqui, para as quais há um número maior de PWs, as linhas de referência são visualmente perceptíveis. Essa característica tonal foi estendida à análise do corpus semiespontâneo desse estudo. 
gama tonais relacionados a essas linhas, que estruturam tonalmente e entoacionalmente os enunciados a partir de domínios sintáticos ou prosódicos (GUSSENHOVEN, 2004). Portanto, investigações mais robustas são requeridas para definirmos status prosódico desse movimento tonal e, a partir disso, traçarmos paralelos quer com variedades de português e outras línguas que possuem acentos frasais, quer com as línguas que fazem uso de mudanças de registro e de gama tonal.
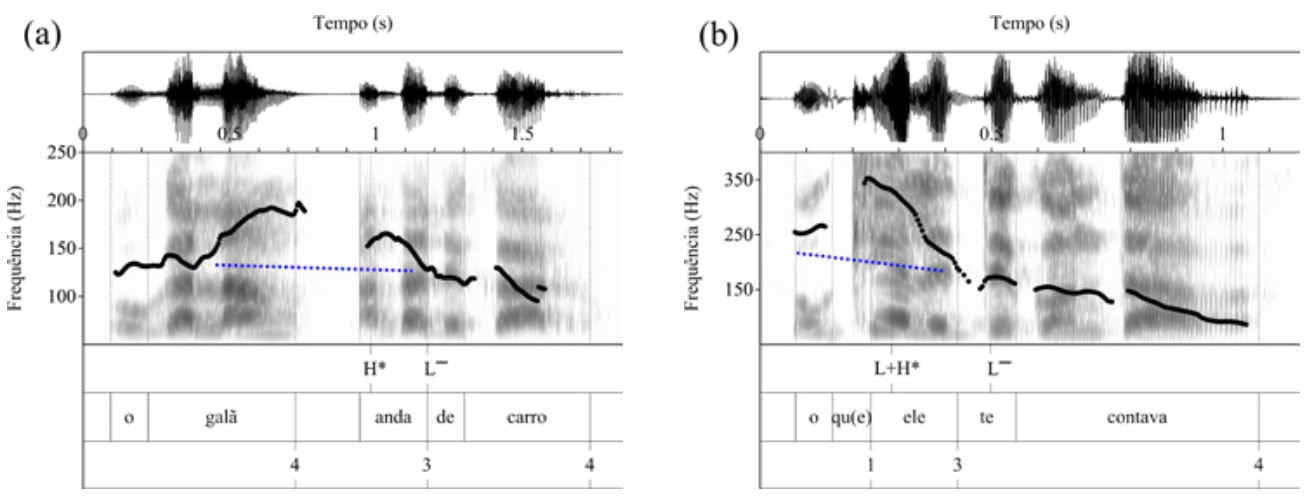

Figura 4. Declarativa neutra 'O galã anda de carro' e interrogativa parcial neutra 'O que ele te contava?' produzidas por AJ e SF, respectivamente

Fonte: Elaboração própria.

\section{Conclusão e considerações finais}

Seguindo uma abordagem Autossegmental-Métrica da entoação integrada à Fonologia Prosódica, este estudo descreve, analiticamente, os eventos tonais associados ao contorno pré-nuclear de declarativas e interrogativas globais e parciais neutras do português angolano do Libolo a partir de dados de fala semiespontânea.

Os resultados atestam uma frequente associação de acentos tonais às palavras fonológicas pré-nucleares, semelhantemente ao que ocorre nas variedades brasileira, guineense e santomense de português (e.g. TENANI, 2002; FERNANDES, 2007; TONELI, 2014; SANTOS; BRAGA, 2017). Se considerarmos que um sintagma fonológico pode se reestruturar com a palavra fonológica subsequente que contém um proclítico, as palavras fonológicas sem acento tonal são majoritariamente não cabeça desse sintagma. Entre os acentos tonais, os ascendentes $L_{+} H^{*}$ e $L^{*}+H$ e o alto $H^{*}$ são os mais comuns no contorno pré-nuclear dos três tipos frásicos, sendo o último exclusivo da posição inicial da sentença.

Além disso, a fronteira entre os dois sintagmas prosódicos (quer sejam analisados como sintagmas fonológicos quer como palavras fonológicas) mais à direita de sentenças 
declarativas e interrogativas parciais pode ser marcada por um possível acento frasal baixo, caso ele não seja interpretado como decorrente da realização do contorno nuclear abaixo de uma linha de referência de tons L. Embora encontrado em uma posição específica, como na variedade alentejana do português europeu, dados externos ao corpus do presente estudo atestam sua ocorrência em diversas posições da sentença, assemelhando esse evento tonal aos acentos frasais encontrados no português guineense e santomense.

Em etapas futuras, além de considerarmos a exequibilidade de testes estatísticos para os dados, consideraremos também a análise do contorno pré-nuclear desses três tipos frásicos em outros estilos discursivos, como a leitura e a fala espontânea, por exemplo, para que, junto aos resultados aqui encontrados, se consolide a caracterização prosódica do português libolense e as hipóteses ora levantadas sejam testadas.

\section{REFERÊNCIAS}

ARAÚJO, P. J. P.; PETTER, M. M. T.; JOSÉ, J. A. Variedade de português angolano e línguas bantas em contato. In: OLIVEIRA, M. S. D.; ARAUJO, G. A. (org.). Português na África Atlântica. São Paulo: Humanitas-FAPESP, 2018. p. 17-45.

BOERSMA, P.; WEENINK, D. Praat: doing phonetics by computer. Versão 6.0.40. 2018. Disponível em: http://www.fon.hum.uva.nl/praat/. Acesso em: 15 set. 2018.

BRAGA, G. Prosódia do português de São Tomé: o contorno entoacional nas sentenças declarativas neutras. 2018. Dissertação (Mestrado em Letras) - Faculdade de Filosofia, Letras e Ciências Humanas, Universidade de São Paulo, São Paulo, 2018.

BRITO, A. M.; DUARTE, I.; MATOS, G. Estrutura da frase simples e tipos de frases. In: MATEUS, M. H. M. et al. (org.). Gramática da Língua Português. 5. ed. Lisboa: Caminho, 2003. p. 273-913.

CARDOSO, S. A. M. S. et al. Atlas linguístico do Brasil. v. 2. Londrina: EDUEL, 2014.

CASTELO, J. A entoação dos enunciados declarativos e interrogativos no português do Brasil: uma análise fonológica em variedades ao longo da Costa Atlântica. 2016. Tese (Doutoramento em Linguística) - Universidade de Lisboa, Lisboa, 2016.

CRUZ, M. Prosodic variation in European Portuguese: phrasing, intonation and rhythm in central-southern varieties. Thesis (PhD in Linguistics) - Universidade de Lisboa, Lisboa, 2013. 
FERNANDES, F. R. Ordem, focalização e preenchimento em português: sintaxe e prosódia. 2007. Tese (Doutorado em Linguística) - Instituto de Estudos da Linguagem, Universidade Estadual de Campinas, Campinas, 2007.

FERNANDES-SVARTMAN, F.; BARROS, N.; SANTOS, V. G.; CASTELO, J. Intonational phrasing and nuclear configurations of SVO sentences across varieties of Portuguese. In: CRUZ, M.; OLIVEIRA, P.; FROTA, S. (ed.). Prosodic variation (with)in languages: intonation, phrasing and segments. Sheffield, UK: Equinox Publishing. A sair.

FIGUEIREDO, C. F. G. Aspectos histórico-culturais e sociolinguísticos do Libolo: aproximações com o Brasil. In: OLIVEIRA, M. S. D.; ARAUJO, G. A. (org.). Português na África Atlântica. São Paulo: Humanitas-FAPESP, 2018. p. 47-100.

FIGUEIREDO, C. F. G.; JORGE, L. T. L.; OLIVEIRA, M. S. D. Clítico argumental "Ihe" no português do Libolo: estrutura formal e caso (abstracto). In: FIGUEIREDO, C. F. G.; OLIVEIRA, M. S. D. (org.). 'Projeto Libolo' - Município do Libolo, Kwanza-Sul, Angola: aspectos linguísticoeducacionais, histórico-culturais, antropológicos e sócio-identitários. v. 1. Lisboa: Chiado, 2016. p. 253-264.

FIGUEIREDO, C. F. G.; OLIVEIRA, M. S. D. Português do Libolo, Angola, e português afroindígena de Jurussaca, Brasil: cotejando os sistemas de pronominalização. PAPIA Revista Brasileira de Estudos do Contato Linguístico, v. 23, n. 2, p. 105-185, 2013.

FROTA, S. Prosody and focus in European Portuguese. Phonological phrasing and intonation. New York: Garland Publishing, 2000.

FROTA, S. The intonational phonology of European Portuguese. In: JUN, S.-A. (ed.). Prosodic typology II. Oxford: Oxford University Press, 2014. p. 6-42.

FROTA, S. et al. Intonational variation in Portuguese: European and Brazilian varieties. In: FROTA, S.; PILAR, P. (ed.). Intonational variation in Romance. Oxford: Oxford University Press, 2015. p. 235-283.

FROTA, S.; PRIETO, P. (ed.). Intonation in Romance. New York: Oxford University Press, 2015.

GUSSENHOVEN, C. The phonology of tone and intonation. New York: Cambridge University Press, 2004. 
HAYES, B.; LAHIRI, A. Bengali intonational phonology. Natural language \& linguistic theory, v. 9, n. 1, p. 47-96, 1991.

JUN, S.-A. (ed.). Prosodic typology II: the phonology of intonation and phrasing. New York: Oxford University Press, 2014.

JUN, S.-A. (ed.). Prosodic typology: the phonology of intonation and phrasing. New York: Oxford University Press, 2005.

LADD, D. R. Intonational phonology. $2^{\text {nd }}$ ed. Cambridge: Cambridge University Press, 2008 [1996].

MORAES, J. A. The pitch accents in Brazilian Portuguese: analysis by synthesis. In: BARBOSA, P.; MADUREIRA, S.; REIS, C. (ed.). Speech Prosody 2008: fourth conference on speech prosody. Campinas: RG-CNPq, 2008.

NESPOR, M.; VOGEL, I. Prosodic phonology. Dordrecht: Foris, 1986.

PIERREHUMBERT, J. The phonology and phonetics of English intonation. 1980. Thesis (PhD)- Massachusetts Institute of Technology, Cambridge, Mass., 1980.

ROSIGNOLI, C. C. O padrão entoacional das sentenças interrogativas da variedade paulista do português brasileiro. 2017. Dissertação (Mestrado em Letras) - Faculdade de Filosofia, Letras e Ciências Humanas, Universidade de São Paulo, São Paulo, 2017.

SANTOS, V. G. Aspectos prosódicos do português de Guiné-Bissau: a entoação do contorno neutro. 2015. Dissertação (Mestrado em Letras) - Faculdade de Filosofia, Letras e Ciências Humanas, Universidade de São Paulo, São Paulo, 2015.

SANTOS, V. G.; BRAGA, G. Associação tonal em sentenças declarativas neutras do português de Bissau e de São Tomé. PAPIA - Revista Brasileira de Estudos do Contato Linguístico, v. 27, n. 1, p. 67-92, jan.-jun. 2017.

SANTOS, V. G.; FERNANDES-SVARTMAN, F. R. Padrões tonais nucleares de declarativas e interrogativas neutras do português angolano do Libolo. Linguística, 2020. (a sair)

SERRA, C. R. Realização e percepção de fronteiras prosódicas no português do Brasil: fala espontânea e leitura. 2009. Tese (Doutorado) - Faculdade de Letras, Universidade Federal do Rio de Janeiro, Rio de Janeiro, 2009. 
TENANI, L. E. Domínios prosódicos no português do Brasil: implicações para a prosódia e para a aplicação de processos fonológicos. 2002. Tese (Doutorado em Linguística) - Instituto de Estudos da Linguagem, Universidade Estadual de Campinas, Campinas, 2002.

TONELI, P. M. A palavra prosódica no português brasileiro. 2014. Tese (Doutorado em Linguística) - Instituto de Estudos da Linguagem, Universidade Estadual de Campinas, Campinas, 2014.

VIGÁRIO, M. Aspectos da prosódia do Português Europeu: estruturas com advérbio de exclusão e negação frásica. Braga: CEHUM, 1998.

VIGÁRIO, M. The prosodic word in European Portuguese. Berlin/New York: Mouton de Gruyter, 2003.

VIGÁRIO, M. Prosodic structure between the prosodic word and the phonological phrase: recursive nodes or an independent domain? The linguistic review, v. 27, n. 4, p. 485-530, 2010.

VIGÁRIO, M.; FROTA, S. The intonation of Standard and Northern European Portuguese. Journal of Portuguese Linguistics, v. 2, n. 2, p. 115-137, 2003. Special Issue on Portuguese Phonology edited by W. Leo. Wetzels.

XAVIER, F. S. Fonologia segmental e supra-segmental do quimbundo: variedades de Luanda, Bengo, Quanza Norte e Malange. 2010. Tese (Doutorado em Linguística) - Faculdade de Filosofia, Letras e Ciências Humanas, Universidade de São Paulo, São Paulo, 2010. 